\title{
Institutional Innovation in Central Europe
}

\section{Peter Darvas}

Peter Dorvos, Visiting Fellow, at the Institute for Human Sciences, Spittelaver Londe 3, A-1090 Vienna, Aurfria, tel: (43I) 313 58-0, fax: (431) 313 58-30,e-mail: pdarvas@iwm. univie.cc. at].

$\mathrm{T}$ he prolonged transition in Central and Eastern $\mathrm{Eu}-$ rope kept higher education in turmoil. Parliaments are already debating amendments to the freshly enacted higher education,laws, and governments experiment with different ways of making the system more effective and responsive. Leaders of public opinion are even more divided on various strategies of expansion and/or restriction, calling for more elite provisions or for building massive structures. Meanwhile, little is known about reform efforts at the level of institutions. Although the challenge and attraction to renew programs and organizations is clear, the potential innovators face formidable dilemmas and roadblocks. Building new institutions when sponsorship for public services is ever more limited, answering new and changing demands, building new academic traditions without solid foundations are missionary acts, calling for international praise and support.

In 1994 the Institute for Human Sciences in Vienna developed, with the financial support of the Korber Foundation (Hamburg), the Hannah Arendt Prize as a means of recognizing institutions that have distinguished themselves through self-initiated reform projects.' The Prize is awarded annually to the most remarkable institutional innovation in the humanities, social sciences, or public policyprograms. Based on the information that has been gathered through the nomination process, we began analyzing the possibilities, strategies, and problems of institutional innovation in four countries of the Central European region: the Czech Republic, Hungary, Poland, and Slovakia.'

The humanities offer challenging fields for renewal, as political control under the Communist regimes had caused the most damaging effects here. The humanities and social sciences were pushed to the periphery of academia, as science and technologywere given dominant support and attention. Academic distinction and excellence have been thwarted,independencewould often yield sanctionsinstead of rewards; academic training was intended to serve rather all-pervasive ideologicaland political goals. The curricular frameworkwas distorted as disciplinesand intellectualfields were "vocationalized."

Not surprisingly, the examined case studies offered a wide range of general goals for innovators. We began to analyze the following successful institutional innovations: - Building entirely new institutions: the case of a new Slovakianinstitute, the Academia Istropolitana, represents one of the most ambitious undertakings. There, the leaders' main goal has been to challenge traditional higher educational institutions by responding more flexibly to the demands of the labor market and offering training in previously "obscure" programs like public administration, applied economics or environmental policy.

\section{The humanities offer Challenging fields far renewal, as political control under the Communistregimes had caused the most damaging effectshere.}

- Restructuring disciplines: such an endeavor was undertaken by the Center for Economic Research and Graduate Education at Charles University, in Prague, to provide, under the guidance of mostly U.S.-based scholarship, a more professional economics training that may set the standards for the entire region.

- Systematizingdoctoral studies. the Graduate School for Social Researchin Warsaw combines the previouslysegregated resources of the best universities in the country and the research institutes of the Academy of Sciences to provide a structured program of doctoral training in various fields of social science research.

- Replacing old hierarchies of knowledge: the Institute of Fundamental Learning was established at Charles University to replace the Marxist-oriented social science and humanities curriculum in bachelor's training and offer new master's programs.

- Diversifying undergraduate programs: renowned social scientists from the research institutes of the Hungarian Academy of Sciencesjoined with the leadership of a Teacher Training College in the small border town of Szombathely to contribute to the College's planned expansion by renewing old social science programs and developing a new field, the Program of European Studies.

- Creating new foundations for high level knowledge: the Center for Theoretical Studies in Prague was established as an institution for advanced studies, to develop the theoretical foundations for the sciences and humanities across disciplines.

- Promoting excellence in student development: the best traditions of the elite colleges within the existing frame- 
work of universities have been revived in Budapest by the Invisible College and by the Rajk Laszlo College of Advanced Studies, both of which promote the traditions of excellence, self-governance, and new pedagogical and teaching methods, as well as new ways of cooperation between students and faculty.

Most of these new institutions and programs have been established during the last five to six years and appear, for now, to be constrained only by the limited sources of support. Yet our experience, learning from these innovative institutions, is that money may not he the only critical factor or not even the most important one.

\section{Focus on Leadership}

Most innovationshave relied heavily on the formal or spiritual guidance of top managers, usually the founders of the new institutions. These leaders often feel that the legitimacy of the institution is based on their exclusive understanding of its goals and operations. They feel that an over-regulated internal structure would only slow things down. The founders, although coming from the academic community, often use political influence and networking capabilities to create their institutions and to maintain support for them. Therefore, their work involves struggles in the ever-changingexternalpolitical arena. This process calls for more flexible but also less transparent internal organizational and management structures. The prominence of leaders could put the existence of the new institutions at risk for leaders can decide to quit before building a solid organizational and administrative structure. In the absence of appropriate professional support, such people arc vulnerable to personal or political criticism.

\section{Recruitment strategies}

The excellence of innovative academicinstitutions is evident in their recruitment strategies. Although new institutions cannot afford to employ full-time faculty for their ambitious trainiig programs, they do not need to do so, because they can survive with part-time staff.Members of the academic community have been strongly motivated to find alternative forms of professional involvement and income: (1) to compensatefor the lackofincentives to achieve excellence elsewhere and (2) to supplement their low salaries in both relative and absolute terms. Educators typically teach in several training sites, and scholarstry to "sell" their professionalexpertise as consultants. Under these conditions, innovative academic initiatives can offer new sources of both income and acknowledgment.

The eight innovativeinstitutions claim up to 40 to 60 of the best (usually senior) scholars in their respective countries as part-time faculty, with only 2 to 6 full-time em- ployees. This employment policy, however, reinforces the reliance on existing intellectual traditions and fields of knowledge. Therefore, new institutions often try to integrate foreign scholarship by inviting visiting professors. On the other hand, the dominance of visiting professorshipcan limit the stabilization of the disciplinary and training programs. In addition to part-time faculty and visiting professors there is the option of recruiting new scholars on a full-timebasis. However, it will take a longer period of time for the new institutions to be able to educate and employ their own faculty.

Each of the four countries maintained or even reinforced the selective nature of their education systems. Higher education in the region enjoys an elite position in general, as students go through a period of selection and tracking at the secondary level and during the transition to higher education. Despite a significant expansion since 1989, only 10 to 15 percent of age-cohorts gain admission to higher education.

The new innovativeinstitutions typically claim additional exclusivity by aiming to gobeyond the standard bachelor'slevel training. According to their self-design, the elitism in higher education needs to be materialized by educational excellence. Typically, the new institutions used strict admission policies, resulting in the admission of every third or every ffth applicant. As an extreme case, Invisible College admitted, during its first year, 26 students out of the 310 applicants.

\section{Strategies \& program development}

Innovative leaders need to divide their focus between developing the organization of their newly established institution and solidifying the disciplinary and program structure. However, the latter brings new problems or challenges. The development of new training programs is jeopardized hy shaky legal foundations. Governments insist on keeping accreditation in their hands and typically behave inflexibly. Traditional academicinstitutions arc also suspicious about the independent ideas of the new academic institutions. Traditional universities often try to influence changes in the national laws to gain a solid independent statute for themselves.

Institutional innovation is principally aimed at developing brand new programs, sometimes without appropriate experience or professional lirks to the field. This can, of course, make them more dependent on externalprofessional guidanceand foreign guest lectures or "travel agency"-type faculty recruitment. Also, the new institutions may find it difficult to predict the expectations of changing societieswhether, for instance, elite education will retain its tradi- 
tionally important role, or more applied services will gain new attraction. Furthermore, it is even more difficult to find the intellectual resources to serve those emergingnew needs.

\section{Clearly, the involvement ofinternational sources in developing humanities pro- grams is a crueial opportunity for the innovators.}

Often, these resources are found in the traditional hierarchies of the academic community. The departure from Marxist or simply monolithic curricular and disciplinary frameworks is rarely initiated from the'peripheries. Leaders are aware that new academic traditions and fields cannot grow overnight; new institutions need to rely on the scholarship with the highest post-Marxist prestige and recognition of the still monolithic academic system. Typically, all the acknowledged innovative institutions were established or initiated by members of either the central universities or the academies of sciences, usually in the capital cities of the four countries. Only the Program of European Studies was physically established in a peripheral region, and only Academia Istropolitana was designed to offer to substitute for the programs of the main Slovakian universities. A trend toward diversification can often mean in reality restriction and replacement. Also, the new institutions often try, after only a year of existence, to continue to expand in size and range to he attractive for new sources of sponsorship. Expansion can, however, also increase their dependence on external agencies.

\section{Sponsorsbip strategies}

The new innovative efforts in higher education are competing for increasingly scarce sources of support, given the overall economiccrisisin the respectivecountries. The need for sponsorship and funds may be one important reason for using political networks, relying on existing academic sources, having few full-timeemployees, and building small elite programs. Beyond these general trends, the examined institutions differ in what they consider to be the optimal strategy. Our analysis has helped to gain a few insights into what seems to be less preferred by the institutionalleaders.

Since the state budgets and public policies are in the process of restructuring, continued reliance on the predominantly public subsidies may not necessarily promise long-term sustainability for new institutions. The states may serve them best by providing initial investments and subsi- dized facilities. Diversified private and international sponsorship, on the other hand, can provoke suspicion in the still politicized academic atmosphere as well as among government officials. Money does not always bring more money. Sustainability, successfultapping of foreign sources, or indication of efficient budgeting could even result in jealousy and malevolence in the contested national academic arena. However, a planned deficit, or openness about financial gaps and potential disasters could also backfire in these changing societies. In sum, the optimal financialmategy seems to be based on a fine balance between public and private, national and international sources, transparency and margins for flexible fund raising and financial management.

Clearly, the involvement of international sources in developing humanities programs is a crucial opportunity for the innovators. The new institutions may attract significant foreign, national, private and international financial support as well as professional expertise. The key problem here for local innovators is how to balance financial and professional support. Once they concentrate "too much" on the first, they could be pressured to make unplanned professional concessions, including hosting too many visiting professors and guest lectures or adopting new programs and functions, dictated hy the sponsors.

International cooperation can result in globalizing communication and knowledge, affecting both sides. The "foreign" side has an opportunity to be effective at sites of academic innovation as those have been defined by local innovators. Thus, they also gain more relevant knowledge of changing societies from their professional and disciplinary perspectives. The "local" innovators could also gain international recognition and an opportunity to integrate their scholarship into the mainstreams of academic exchange.

\section{Notes}

1. The prize is part of the Institute's larger project on "The Transformation of the National Higher Education and Research Systems of Central Europe." More information on the project can be acquired from Dr. Jocken Fried, Program Director, Institute for Human Sciences [Spittelauer Lande 3, A-1090 Vienna, Austria, tel(431) 313 58-0, fax: (431) 313 58-30, e-mail: fried@iwm.univie.ac.at].

2. Our analysis is aimed at developing a foundation for a more systematic research into a better understanding of the main strategies and problems of institutional innovation, as well as to formulate recommendations on how to support innovativepractices, help the best institutions to gain further acknowledgment, and to establish fora of information exchange. Inquiries about the research project can be sent to Dr.PeterDarvas, Visiting Fellow, at the Institute for Human Sciences [SpittelauerLande 3, A-1090 Vienna, Austria, tel(431) 313 58-0, fax: (431) 313 58-30, e-mail: pdarvas@iwm.univie.ac.at]. 